\title{
Strandings of striped dolphin Stenella coeruleoalba in Scottish waters (1992-2003) with notes on the diet of this species - CORRIGENDUM
}

M.B. SANTOS, G.J. PIERCE, J.A. LEARMONTH, R.J. REID, M. SACAU, I.A.P. PATTERSON AND H.M. ROSS doi:10.1017/So025315408000155, Published online by Cambridge University Press 17 March 2008.

In the article by Santos et al. (2008) incorrect versions of Figures 2 and 3 were inadvertently included. The correct versions are provided below. The main conclusions of the article are unchanged. We apologise to readers for this error.

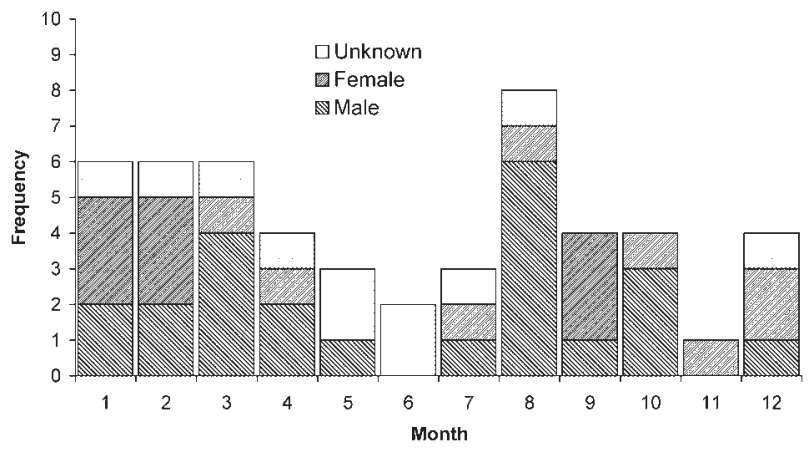

Fig. 2. Seasonal distribution of striped dolphin (Stenella coeruleoalba) strandings around the Scottish coast (1992-2003).

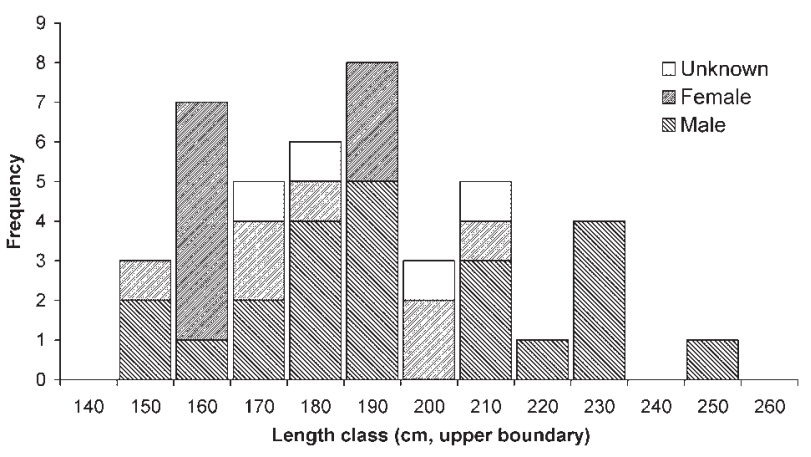

Fig. 3. Length distribution of stranded striped dolphin (Stenella coeruleoalba) around the Scottish coast (1992-2003).

First published online 31 October 2012

\section{REFERENCE}

Santos M.B., Pierce G.J., Learmonth J.A., Reid R.J., Sacau M., Patterson I.A.P. and Ross H.M. (2008) Strandings of striped dolphin Stenella coeruleoalba in Scottish waters (1992-2003) with notes on the diet of this species. Journal of the Marine Biological Association of the United Kingdom doi:10.1017/Soo25315408000155. Published online by Cambridge University Press 17 March 2008. 